\title{
Reflections on an International "Change Institute" for Students as Partners: A Student Perspective
}

Anita Acai Department of Psychology, Neuroscience \& Behaviour \& Office of Education Science, Department of Surgery, McMaster University, Hamilton, Ontario, Canada.

Contact: acaia@mcmaster.ca

Sabrina Kirby, Faculty of Information, University of Toronto, Toronto, Ontario, Canada.

Rafaella Shammas Department of Biochemistry and Biomedical Sciences, McMaster University, Hamilton, Ontario, Canada.

\section{INTRODUCTION}

In May 2016, the Paul R. MacPherson Institute for Leadership, Innovation, and Excellence in Teaching at McMaster University (formerly known as the McMaster Institute for Innovation and Excellence in Teaching and Learning) hosted its inaugural Summer Institute on Students as Partners. The purpose of this international event was to "build the capacity and understanding of faculty, staff, and students to develop, design[,] and implement initiatives to promote the practice of Students as Partners in teaching and learning" (MacPherson Institute, 2016). Over the span of 3 days, teams comprised of faculty, staff, and student partners had the opportunity to participate in either the workshop program or the Change Institute $(\mathrm{Cl})$, both of which were organized and facilitated by students and faculty/staff partners.

The workshops offered attendees opportunities to explore how student partnerships can be fostered in an array of contexts such as in teaching, learning, and assessment; subjectbased inquiry and research; curriculum design and pedagogical consultancy; and the Scholarship of Teaching and Learning (Healey, Flint, \& Harrington, 2014). Simultaneously, the $\mathrm{Cl}$ offered a program for teams to develop their institution-specific students-as-partners initiatives and interact with other teams during sessions led by students and faculty/staff facilitators. Student partners played an instrumental role in the $\mathrm{Cl}$, from organizing to planning and facilitating workshops and sessions. The philosophy of Students as Partners was therefore threaded throughout, making the $\mathrm{Cl}$ a unique opportunity for all involved.

In this reflective essay, we describe our experiences as three student facilitators and consultants at the MacPherson Institute's inaugural $\mathrm{Cl}$. The questions that we have chosen to reflect on in this essay come from an exercise in which we each thought of two questions for reflection, collated these in a document, and then produced individual, written responses for 
each. We then met as a group to decide which questions we felt best captured our experiences at the $\mathrm{Cl}$ and could offer others interested in building their own students-as-partners initiatives some useful insights (for example, how assumptions often get in the way of engaging in partnership or how failure can be an important element in the process of building successful partnerships). In further refining our chosen questions and responses to write this essay, we chose to retain our individual voices and perspectives (Werder, Thibou, \& Kaufer, 2012), recognizing that each of us approached the partnership experience with our own set of assumptions and experiences and thus have a unique perspective to share.

\section{In what ways was partnership enacted throughout the $\mathrm{Cl}$ ?}

Rafaella: As a student facilitator and consultant at the $\mathrm{Cl}$, I especially enjoyed the freedom in articulating my thoughts and using my expertise to help teams navigate through their projects. This was largely due to the efforts of committed staff partners who made us feel welcomed and included in the entire process. For example, as student partners, we were invited to all relevant operational planning meetings and social events. In this way, the $\mathrm{Cl}$ represented the kind of socialization that Kotzé and du Plessis (2003), in an article on students as co-producers, identify as being a key component of student engagement and sense of purpose. We were also encouraged to actively and creatively participate in various aspects of the $\mathrm{Cl}$, including drawing from past partnerships to frame our sessions. For example, my experience helping to construct a model for a new Leadership in Teaching and Learning Fellowship Program as part of the MacPherson Institute's Student Partners Program (SPP; Cockroft et al., 2016) helped me gain experience in sharing my ideas about program development with both students and faculty/staff in a multidisciplinary environment.

Anita: Having opportunities to build relationships with my student and faculty/staff partners before the $\mathrm{Cl}$ took place created trust and openness among our team members, which made for a strong partnership experience. We knew what working with each other would be like and felt comfortable sharing our thoughts with one another -things that can often take a long time to establish when working in partnership. I also felt that the $\mathrm{Cl}$ was helpful for consolidating what I had learned in prior partnerships and allowed me to reflect upon these lessons in new ways. For example, in a past partnership experience, I recall often feeling frustrated and let down because I did not feel adequately supported by my faculty partner in terms of their time commitment to the project. But, in reflecting on what I had learned at the $\mathrm{Cl}$ and some of my more recent partnership experiences that have been much more positive, I realized that I never actually articulated to them how I was feeling because I was too afraid of offending them. It often seems easier to try to avoid the uncomfortable moments of partnership at the risk of offending those with whom we have close working relationships, but learning how to articulate how we are feeling and what it is that we need from our partners is an important part of upholding our end of the partnership "bargain."

Sabrina: The embedded quality of partnership as it was enacted throughout the $\mathrm{Cl}$ contributed immensely to my overall level of engagement with the process. Because I was meaningfully involved in the early planning stages of the $\mathrm{Cl}$, I felt a sense of ownership and pride over the work we were doing. Importantly, I felt that I could be critical. I spoke up when I noticed that we needed to provide additional opportunities for intergroup collaboration and found that my suggestions were actually valued. Moreover, the Cl's commitment to partnership 
at the planning stage prevented the contributions of student facilitators from becoming tokenized. As a result, I was able to interact with the faculty/staff members involved in a far more meaningful and equitable manner than I would have been able to had we been operating within the traditional hierarchical paradigm of student-faculty/staff collaborations.

\section{Were there any assumptions you made coming into the $\mathrm{Cl}$ ? In what ways did your experience as a student partner challenge some of these assumptions?}

Rafaella: When I was asked to facilitate a couple of sessions and act as a student consultant at the $\mathrm{Cl}$, I found myself both surprised and excited at the thought of having students run a conference-style session for faculty/staff and their student partners. But I also went into the $\mathrm{Cl}$ wondering if my contributions would be relevant or even meaningful to the teams I interacted with-until I walked into a room packed with student partners from across the globe! It was confidence-inspiring to see other student partners being part of the operational planning committee, facilitating workshops, and taking the lead on their own partnership projects. The $\mathrm{Cl}$ not only provided opportunities for teams to build upon and strengthen their partnerships, but it also became a space for important discussions that encompassed a variety of perspectives. For instance, during the $\mathrm{Cl}$, I facilitated a discussion on developing partnership learning communities where students and faculty shared their perspectives about fostering self-generating and powerful learning communities. I became much more excited and confident about participating in the conversation, enabling me to contribute to teaching and learning in ways I could have never imagined when I first started.

Anita: Having read about each team's project and goals for the $\mathrm{Cl}$ in advance of their arrival, I realized that I had made a number of assumptions about each project team - for example, where they were in the process, the way that power might play out in their partnership, or some of the challenges that they might face in developing their initiative. While some of these assumptions proved to be true, others did not. I realized that an essential part of my role was putting assumptions aside and taking the time to get to know each team while they were at the $\mathrm{Cl}$. It was important that members of each team be the ones to tell me about their roles, goals, and expectations rather than the other way around. This is also applicable to partnership more broadly, where it is important to recognize how our assumptions may shape how we interpret the perspectives or actions of our partners. It was also interesting to see some of the teams' roles, goals, and expectations shift over time, which reminded me of the dynamic nature of partnership and the importance of flexibility and adaptiveness on the part of all involved, including those of us serving as facilitators and consultants.

Sabrina: Given my prior experience as a student partner, I carried some assumptions about what partnership looked like into my work with the $\mathrm{Cl}$. My understanding of my university's institutional structure led to the mistaken impression that student partnership initiatives would always or even often originate within institutional structures that are explicitly pedagogical in their nature and purpose (i.e., teaching and learning centres). I quickly came to realize the narrowness of my assumption: Partnership projects can be conceived of and facilitated at every level from the individual classroom to high levels of administration. The diversity of approaches, from engaging students as curriculum consultants to creating studentled mentorship programs, created a rich environment for the exchange of ideas and ample opportunities for collaboration both within and between institutions. Significantly, I discovered 
that the principles and strategies of partnership I had learned through the SPP at MacPherson (for example, authenticity, honesty, inclusivity, reciprocity, empowerment, trust, courage, plurality, and responsibility [Higher Education Academy, 2015]) were much more widely relevant than I had initially believed and were in fact applicable to a vast array of projects and scenarios. Understanding this has allowed me to enact these principles in subsequent collaborations and to form more meaningful professional relationships.

\section{What were some of your most significant "lessons learned" from this partnership experience that you will take with you moving forward?}

Rafaella: Prior to the $\mathrm{Cl}$, I was unaware that I had the skills to act as a student consultant. One of my tasks was to consult with one team who planned to implement an initiative that I was worried did not authentically engage students in partnership. I posed a few questions that compelled the team to think differently about their project-for example, would the students working as part of this initiative have the resources they would need in order to carry out the intended project goals? How might the team go about ensuring that their studentled initiative would be sustainable from year to year? As the $\mathrm{Cl}$ progressed, they were able to utilize some of the frameworks we presented to successfully create a project plan, which I felt integrated the philosophy of student partnerships in a meaningful way. It was rewarding to see that an idea I proposed had helped this team move forward. Although they expressed that they still had plenty of work left to do, I recall their gratitude for having the concentrated amount of time to work closely with their partners.

Anita: Much like my fellow student partners, I had not had much consulting experience prior to the $\mathrm{Cl}$, nor had I ever built a students-as-partners initiative from the ground up like many of our teams were doing. Although I had done lots of things as part of the SPP at MacPherson-from examining the impact of a national teaching fellowship program to creating an international database of the literature on Students as Partners - it was so much easier to think about the skills that I didn't have as opposed to the ones I did. I also had reservations about facilitating activities in front of such a large group of people since I have never considered public speaking to be one of my strengths. But, coming away from this experience, I felt that I had made a positive contribution as both a facilitator and a student consultant, and I felt more confident in my ability to do both. A couple of attendees complimented me on my public speaking abilities, which helped me become more confident in this area. I also realized that while I may not have had prior experience as a consultant, my perspective as a student was valuable to the teams and was something that people were interested in.

Sabrina: I came to appreciate the importance not only of having trust in your partners, but also knowing that they have trust in you. At the time of the $\mathrm{Cl}$, I had just completed my undergraduate degree. Although I had previously worked as a student partner at the MacPherson Institute, I was still uncomfortable with the notion of speaking from a position of expertise to teams of attendees comprised at least in part of faculty/staff and university administrators. As I was embarking on a completely new and unfamiliar role, it was no surprise that I experienced what others have described as imposter syndrome (Parkman, 2016). I feared that I would not be taken seriously, or worse yet, that my knowledge would somehow prove insufficient. However, it was clear from the very beginning of our work together on this project that my faculty partner did not share my reservations. Her trust and support enabled me to 
draw upon experiences from inquiry-based courses in my undergraduate degree to assist a group at the $\mathrm{Cl}$ in the planning stages of designing a new course. She encouraged me to consult individually with the attendees, both with and without her supervision, and was fully confident in my ability to provide meaningful guidance. In so doing, I was able to realize the full value not only of my knowledge of academic partnership, but also my unique perspective as a student. The experience also demonstrated how faculty confidence in student partners can help students to fully realize their leadership potential.

\section{IMPLICATIONS AND CONCLUDING REMARKS}

As we reflected upon our experiences as student facilitators and consultants at the MacPherson Institute's inaugural $\mathrm{Cl}$, it became very clear to us that this was a positive example of how students can be partners in teaching and learning. Our reflections illustrate the ways in which we felt truly included and valued as students, how some of our initial assumptions about partnership were challenged, and the lessons that we will carry forward. We would like to draw readers' attention to several of these lessons which we feel might help others who are interested in establishing their own student-faculty/staff partnership initiatives.

First, any successful partnership initiative takes time to build. Although 3 days may seem like a short time, the teams who attended the $\mathrm{Cl}$ were given a considerable amount of concentrated work time to make progress on their initiative, regardless of the stage it was at. This time allowed for focused discussion about important elements of the initiative, with a focus on establishing how to move forward on a practical level. Some of the discussions were aimed at finding ways to meaningfully and feasibly integrate student involvement within the specific initiatives. In addition, several teams commented on the value of using impact assessment as the starting point for program development. For example, teams discussed the potential processes/activities within their initiative that they could evaluate and listed specific indicators while planning for their projects, which allowed them to transition from broad ideas to more specific and feasible ones. Teams also used some of the concentrated time to further build their projects, bridge gaps, acknowledge challenges, and work towards more sustainable initiatives. This approach to project development may be particularly beneficial for teams because it affords them the opportunity to think about the various elements of their project free of most distractions and also has the added benefit of allowing teams to get input about their project from others with similar but external perspectives.

Second, working as student facilitators and consultants in the $\mathrm{Cl}$ reaffirmed how much development and change can occur in the span of 3 days, thus illustrating the dynamism that is inherent in student-faculty/staff partnerships. It is, therefore, critical that those engaging in partnership be open to the process of partnership and flexible with respect to roles, goals, and expectations since these things can-and often do-change and evolve as a project progresses.

Third, although the experiences we detailed in this reflection were very positive, they were predicated on our past failures. Had we not experienced partnerships that had not gone well (for example, when we felt disempowered and hesitant about sharing our opinions or felt that we lacked the mentorship we needed to succeed or that our contributions were not valued), we would not have had a good understanding of how to build a good partnership nor how to be effective facilitators. Part of the process of building a good partnership includes acquainting teams with the possibility of failure or even debriefing and rebuilding after a failure 
has already occurred. Therefore, we wish to convey to our readers that past failures or the fear of imperfection should not be a deterrent to building student-faculty/staff partnerships. Failures are often the best learning opportunities for those involved in partnership.

Finally, despite being relatively experienced in terms of our prior involvement in student-faculty/staff partnerships, we each entered the $\mathrm{Cl}$ with some doubt in our abilities to adequately serve as student facilitators and consultants. This illustrates the potential fragility of partnership identities - when we step into new contexts, major doubts can often arise. It was through the support of our faculty/staff partners and the willingness of those present at the $\mathrm{Cl}$ that we were able to grow our confidence and fully immerse ourselves in our roles. From our perspective, therefore, creating a culture that is trusting of students and encourages them to openly share their insights is the most important thing that faculty/staff can do to create a positive partnership experience for their student partners. And, for fellow students who may be experiencing imposter syndrome when faced with the prospect of a new partnership experience: Don't be afraid to step outside of your comfort zone and try something new! We guarantee that you have more to offer than you will initially allow yourself to believe.

\section{ACKNOWLEDGEMENTS}

Thank you to everyone who participated in MacPherson Institute's inaugural Summer Institute. Your talent, passion, and dedication to students-as-partners initiatives were what lead us to uncover many of the insights that we have shared in this reflection. We were particularly honoured to work closely with a talented team of facilitators and organizers over the course of the $\mathrm{Cl}$, including Beth Marquis, Mick Healey, Kris Knorr, and Christine Black. Special thanks to Beth Marquis for your helpful comments with respect to this article, as well as Alison CookSather and Anita Ntem for your editorial feedback and support.

\section{NOTES ON CONTRIBUTORS}

Anita Acai is a PhD student in the Department of Psychology, Neuroscience \& Behaviour at McMaster University.

Sabrina Kirby is a Master of Information student in the Faculty of Information at the University of Toronto.

Rafaella Shammas is an undergraduate student in the Arts \& Science program at McMaster University.

All three authors are participants in the Student Partners Program at the Paul R. MacPherson Institute for Leadership, Innovation, and Excellence in Teaching at McMaster University. 


\section{REFERENCES}

Cockroft, R., Drouillard, T., Faubert, J., Gabay, D., Knorr, K., Liu, A., \& Van Gastel, G. (2016). Student Partners Program guidebook. Hamilton, ON: McMaster Institute for Innovation and Excellence in Teaching and Learning. Retrieved from https://mi.mcmaster.ca/site/wp-content/uploads/2016/11/SPP FinalUpdated2016.pdf

Healey, M., Flint, A., \& Harrington, K. (2014). Engagement through partnership: Students as partners in learning and teaching in higher education. Heslington, UK: The Higher Education Academy. Retrieved from https://www.heacademy.ac.uk/sites/default/files/resources/engagement through part nership.pdf

Higher Education Academy. (2015). Framework for student engagement through partnership. York, UK: Higher Education Academy. Retrieved from https://www.heacademy.ac.uk/sites/default/files/downloads/student-enagagementthrough-partnership-new.pdf

Kotzé, T. G., \& du Plessis, P. J. (2003). Students as "co-producers" of education: A proposed model of student socialisation and participation at tertiary institutions. Quality Assurance in Education, 11(4), 186-201. doi:10.1108/09684880310501377

MacPherson Institute. (2016). International Summer Institute on Students as Partners. Retrieved from https://macblog.mcmaster.ca/summer-institute/

Parkman, A. (2016). The imposter phenomenon in higher education: Incidence and impact. Journal of Higher Education Theory and Practice, 16(1), 51-60.

Werder, C., Thibou, S., \& Kaufer, B. (2012). Students as co-inquirers: A requisite threshold concept in educational development? The Journal of Faculty Development, 26(3), 34-38. 